\title{
Age Based Overhaul Policy for Multiple Repairable Systems with Imperfect Maintenance: Case Study of Aero Engines
}

\author{
Garima Sharma \\ Subir Chowdhury School of Quality and Reliability, \\ Indian Institute of Technology (IIT) Kharagpur, Kharagpur, India. \\ Corresponding author: sharma.garima@iitkgp.ac.in \\ Rajiv Nandan Rai \\ Subir Chowdhury School of Quality and Reliability, \\ Indian Institute of Technology (IIT) Kharagpur, Kharagpur, India. \\ E-mail: rnrai@iitkgp.ac.in
}

(Received March 26, 2020; Accepted May 12, 2020)

\begin{abstract}
Reliability analysis of complex multiple repairable systems (MRS) such as aero engines, rolling stocks and nuclear power plants has always been an area of interest for the research fraternity. An appropriate age based overhaul maintenance policy for such systems can provide impetus to the operations. The paper proposes two different age based maintenance policies; Policy-I and Policy-II, to evaluate the overhaul time of an aero engine, where Policy-I considers MRS with imperfect corrective maintenance (CM), whereas Policy-II examines MRS with both imperfect CM and preventive maintenance (PM). The paper then provides a spare parts estimation model for both the policies. The developed policies and spares parts model are validated by considering field failure data of aero engines as a case and the obtained results are compared with the existing time based maintenance policy used for aero engines. The paper recommends the best policy to be used for MRS in general and the considered case in particular.
\end{abstract}

Keywords- Multiple repairable systems, Age based overhaul, Maximum likelihood estimators, Spare parts, Generalized renewal process.

\section{Introduction}

Complex and large systems such as aero engines or locomotives cannot be treated as non-repairable systems since repair actions (Sheu et al., 2014) are required to be performed when they fail and thus are categorized as repairable systems (RS) (Rigdon and Basu, 2000). Reliability analysis ( Yamamoto et al., 2012) of repairable systems is carried out by treating the system either as a single repairable system (SRS) or multiple repairable systems (MRS) (Garmabaki et al., 2016). In SRS, the failure data of a particular system is considered for reliability analysis whereas in MRS, the failure data of all identical systems working in the field is utilized for reliability analysis. Hence MRS analysis portray a larger picture of the system's condition compared to SRS. Both the systems are represented in Figure 1. 


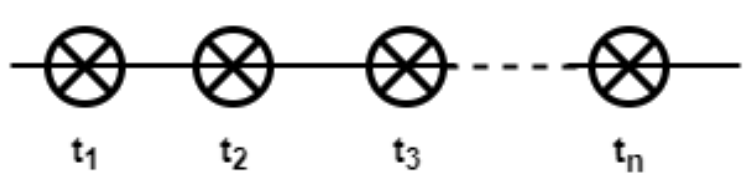

(a)

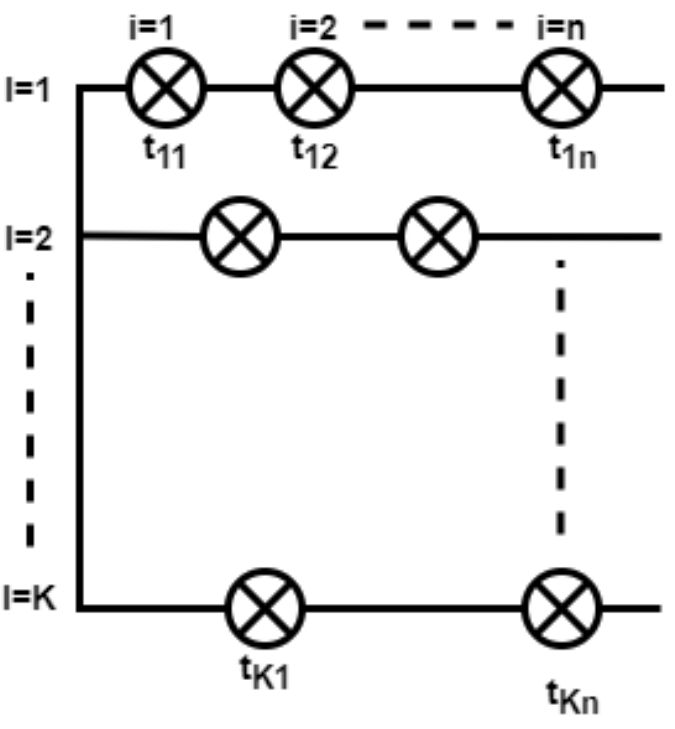

(b)

Figure 1. (a) Single repairable system, (b) Multiple repairable systems.

One of the most reliable model available in the literature for the analysis of RS is the generalized renewal process (GRP) proposed by Kijima (Kijima and Sumita, 1986; Kijima, 1989). The generalized renewal process is based on the virtual age concept and very much appreciated by present research fraternity and also applied extensively for imperfect repair (Brown and Proschan, 1983; Pham and Wang, 1996) reliability analysis. Kijima proposes two virtual age based models: Kijima model I (KI) states that the $\mathrm{i}^{\text {th }}$ repair can only remove the effect of damages incurred since $(\mathrm{i}-1)^{\text {th }}$ repair (equation 1 ) whereas according to Kijima model II (KII) the $i^{\text {th }}$ repair can collectively restore the damages up to the present time (equation 2).

$\mathrm{V}_{\mathrm{i}}=\mathrm{V}_{\mathrm{i}-1}+\mathrm{qy}_{\mathrm{i}}(\mathrm{i}=1,2, \ldots . \mathrm{p})$

$V_{i}=q\left(V_{i-1}+y_{i}\right)(i=1,2, \ldots . p)$

where

$\mathrm{V}_{\mathrm{i}}$ : virtual age at $\mathrm{i}^{\text {th }}$ failure

$y_{i}=r_{i}-r_{i-1}$ (time between failures)

$r_{i}$ : time of $i^{\text {th }}$ failure

p: number of failures

q: repair effectiveness index (REI)

$\mathrm{q}=\left\{\begin{array}{lr}0 ; & \text { for perfect maintenance(as good as new condition) } \\ 0<\mathrm{q}<1 ; \text { for imperfect maintenance(intermediate state) } \\ 1 ; \quad \text { for minimal maintenance(as bad as old condition) }\end{array}\right.$ 
International Journal of Mathematical, Engineering and Management Sciences

Vol. 6, No. 1, 193-206, 2021

https://doi.org/10.33889/IJMEMS.2021.6.1.012

The power law process (PLP) (Rigdon and Basu, 1989) with two reliability parameters, $\beta$ (shape parameter) and $\eta$ (scale parameter) is then modified considering third parameter i.e. ' $q$ '. Later, several attempts are made to estimate these three parameters (Yanez et al., 2002; Mettas and Zhao, 2005). Based on the types of maintenance actions performed on repairable systems i.e. corrective maintenance (CM) and preventive maintenance (PM), Nasr et al. (2013)further propose modified KI model by splitting ' $\mathrm{q}$ ' into two parameters i.e. $\mathrm{q}_{\mathrm{PM}}$ (REI for PM) and $\mathrm{q}_{\mathrm{CM}}$ (REI for CM). The authors also provide likelihood function and maximum likelihood estimators (MLEs) for the model's parameter estimation. The model, its likelihood and log likelihood functions and maximum likelihood estimators (MLEs) as provided by Nasr et al. (2013) are reproduced below for a better understanding of the readers.

The likelihood and Log-likelihood function:

$L($ Data $)=\prod_{i=1}^{n} f\left(\left(t_{i} \mid t_{i-1}\right)\right)$

$f\left(\left(t_{i} \mid t_{i-1}\right)\right)$ is probability density function (pdf)in case of reparable systems

$\mathrm{L}\left(\mathrm{x}_{1}, \mathrm{x}_{2}, \ldots . \mathrm{x}_{3} \mid \beta, \eta, \mathrm{q}_{\mathrm{CM}}, \mathrm{q}_{\mathrm{PM}}\right)=$

$\prod_{1=1}^{\mathrm{K}}\left[\prod_{\mathrm{i}=1}^{\mathrm{n}_{\mathrm{l}}}\left[\left\{\frac{\beta}{\eta}\left(\frac{\mathrm{V}_{\mathrm{l}, \mathrm{i}-1}+\mathrm{x}_{\mathrm{l}, \mathrm{i}}}{\eta}\right)^{\beta-1}\right\}^{\delta_{\mathrm{l}, \mathrm{i}}}\right] \prod_{\mathrm{i}=1}^{\mathrm{n}_{1}} \exp \left\{\begin{array}{c}\left(\frac{\mathrm{V}_{\mathrm{l}, \mathrm{i}-1}}{\eta}\right)^{\beta} \\ -\left(\frac{\mathrm{V}_{\mathrm{l}, \mathrm{i}-1}+\mathrm{x}_{\mathrm{l}, \mathrm{i}}}{\eta}\right)^{\beta}\end{array}\right\}\right]$

where,

$V_{i}=\sum_{j=1}^{i} q_{C M}^{\delta_{j}} q_{P M}^{1-\delta_{j}} x_{i}$ i.e. proposed virtual age model by Nasr et al. (2013)

$\mathrm{x}_{\mathrm{i}}=\mathrm{t}_{\mathrm{i}}-\mathrm{t}_{\mathrm{i}-1}$ (time between intervention)

$t_{i}$ : is time to intervention (either PM or CM)

$\beta$ : shape parameter

$\eta$ : scale parameter

$\mathrm{n}$ : no. of interventions $(\mathrm{i}=1,2, \ldots, \mathrm{n})$

$\mathrm{K}$ : no. of systems $(1=1,2, \ldots, \mathrm{K})$

$\delta_{\mathrm{j}}=\left\{\begin{array}{ll}1 & \text { if } \mathrm{CM} \\ 0 & \text { if } \mathrm{PM}\end{array}\right\}$

Log-likelihood function:

$$
\begin{aligned}
\ln L=\log (\beta) \sum_{\mathrm{l}=1}^{\mathrm{K}}\left[\sum_{\mathrm{i}=1}^{\mathrm{n}_{\mathrm{l}}} \delta_{\mathrm{l}, \mathrm{i}}\right]+(\beta-1) \sum_{\mathrm{l}=1}^{\mathrm{K}}\left[\sum_{\mathrm{i}=1}^{\mathrm{n}_{\mathrm{l}}} \delta_{\mathrm{l}, \mathrm{i}} \log \left(\mathrm{V}_{\mathrm{l}, \mathrm{i}-1}+\mathrm{x}_{\mathrm{l}, \mathrm{i}}\right)\right]- \\
\beta \log (\eta) \sum_{\mathrm{l}=1}^{\mathrm{K}}\left[\sum_{\mathrm{i}=1}^{\mathrm{n}_{1}} \delta_{\mathrm{l}, \mathrm{i}}\right]+\sum_{\mathrm{l}=1}^{\mathrm{K}}\left[\sum_{\mathrm{i}=1}^{\mathrm{n}_{1}}\left[\left(\frac{\mathrm{V}_{\mathrm{l}, \mathrm{i}-1}}{\eta}\right)^{\beta}-\left(\frac{\left(\mathrm{v}_{\mathrm{l}, \mathrm{i}-1}+\mathrm{x}_{\mathrm{l}, \mathrm{i}}\right)}{\eta}\right)^{\beta}\right]\right]
\end{aligned}
$$


International Journal of Mathematical, Engineering and Management Sciences

Vol. 6, No. 1, 193-206, 2021

https://doi.org/10.33889/IJMEMS.2021.6.1.012

Maximum likelihood estimators (MLEs):

$$
\begin{aligned}
& \frac{\partial \log (\mathrm{L})}{\partial \beta}=\sum_{\mathrm{l}=1}^{\mathrm{K}}\left[\sum_{\mathrm{i}=1}^{\mathrm{n}_{1}}\left[\left(\frac{\mathrm{V}_{\mathrm{l}, \mathrm{i}-1}}{\eta}\right)^{\beta} \log \left(\frac{\mathrm{V}_{\mathrm{l}, \mathrm{i}-1}}{\eta}\right)-\left(\frac{\left(\mathrm{V}_{\mathrm{l}, \mathrm{i}-1}+\mathrm{x}_{\mathrm{l}, \mathrm{i}}\right)}{\eta}\right)^{\beta} \log \left(\frac{\left(\mathrm{V}_{\mathrm{l}, \mathrm{i}-1}+\mathrm{x}_{\mathrm{l}, \mathrm{i}}\right)}{\eta}\right)\right]\right]+ \\
& \frac{1}{\beta} \sum_{\mathrm{l}=1}^{\mathrm{K}}\left[\sum_{\mathrm{i}=1}^{\mathrm{n}_{\mathrm{l}}} \delta_{\mathrm{l}, \mathrm{i}}\right]+\sum_{\mathrm{l}=1}^{\mathrm{K}}\left[\sum_{\mathrm{i}=1}^{\mathrm{n}_{\mathrm{l}}} \delta_{\mathrm{l}, \mathrm{i}} \log \left(\mathrm{V}_{\mathrm{l}, \mathrm{i}-1}+\mathrm{x}_{\mathrm{l}, \mathrm{i}}\right)\right]-\log (\eta) \sum_{\mathrm{l}=1}^{\mathrm{K}}\left[\sum_{\mathrm{i}=1}^{\mathrm{n}_{\mathrm{l}}} \delta_{\mathrm{l}, \mathrm{i}}\right]=0 \\
& \frac{\partial \log (\mathrm{L})}{\partial \eta}=-\beta \eta^{-\beta-1} \sum_{\mathrm{l}=1}^{\mathrm{K}}\left[\sum_{\mathrm{i}=1}^{\mathrm{n}_{\mathrm{l}}}\left[\left(\mathrm{V}_{\mathrm{l}, \mathrm{i}-1}\right)^{\beta}-\left(\mathrm{V}_{\mathrm{l}, \mathrm{i}-1}+\mathrm{x}_{\mathrm{l}, \mathrm{i}}\right)^{\beta}\right]\right]-\frac{\beta}{\eta} \sum_{\mathrm{l}=1}^{\mathrm{K}}\left[\sum_{\mathrm{i}=1}^{\mathrm{n}_{1}} \delta_{\mathrm{l}, \mathrm{i}}\right]=0
\end{aligned}
$$

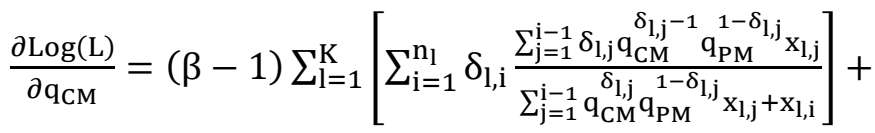

$$
\begin{aligned}
& \frac{1}{\eta^{\beta}} \sum_{\mathrm{l}=1}^{\mathrm{K}}\left[\sum _ { \mathrm { i } = 1 } ^ { \mathrm { n } _ { \mathrm { l } } } \left[\beta\left(\sum_{\mathrm{j}=1}^{\mathrm{i}-1} \delta_{\mathrm{l}, \mathrm{j}} \mathrm{q}_{\mathrm{CM}}^{\delta_{\mathrm{l}, \mathrm{j}}-1} \mathrm{q}_{\mathrm{PM}}^{1-\delta_{\mathrm{l}, \mathrm{j}}} \mathrm{x}_{\mathrm{l}, \mathrm{j}}\right)\left(\sum_{\mathrm{j}=1}^{\mathrm{i}-1} \mathrm{q}_{\mathrm{CM}}^{\delta_{\mathrm{l}, \mathrm{j}}} \mathrm{q}_{\mathrm{PM}}^{1-\delta_{\mathrm{l}, \mathrm{j}}} \mathrm{x}_{\mathrm{l}, \mathrm{j}}\right)^{\beta-1}-\right.\right. \\
& \left.\left.\beta\left(\sum_{j=1}^{i-1} \delta_{l, j} q_{C M}^{\delta_{l, j}-1} q_{P M}^{1-\delta_{l, j}} x_{l, j}\right)\left(\sum_{j=1}^{i-1} q_{C M}^{\delta_{l, j}} q_{P M}^{1-\delta_{l, j}} x_{l, j}+x_{l, i}\right)^{\beta-1}\right]\right]=0 \\
& \frac{\partial \log (\mathrm{L})}{\partial \mathrm{q}_{\mathrm{PM}}}=(\beta-1) \sum_{\mathrm{l}=1}^{\mathrm{K}}\left[\sum_{\mathrm{i}=1}^{\mathrm{n}_{\mathrm{l}}} \delta_{\mathrm{l}, \mathrm{i}} \frac{\sum_{\mathrm{j}=1}^{\mathrm{i}-1}\left(1-\delta_{\mathrm{l}, \mathrm{j}}\right) \mathrm{q}_{\mathrm{CM}}^{\delta_{1, \mathrm{j}}} \mathrm{q}_{\mathrm{PM}}^{-\delta_{1, j}} \mathrm{x}_{\mathrm{l}, \mathrm{j}}}{\sum_{\mathrm{j}=1}^{\mathrm{i}-1} \mathrm{q}_{\mathrm{CM}}^{\delta_{1, j}} \mathrm{q}_{\mathrm{PM}}^{1-\delta_{\mathrm{l}, \mathrm{j}}} \mathrm{x}_{\mathrm{l}, \mathrm{j}}+\mathrm{x}_{\mathrm{l}, \mathrm{i}}}\right]+\frac{1}{\eta^{\beta}} \sum_{\mathrm{l}=1}^{\mathrm{K}}\left[\sum _ { \mathrm { i } = 1 } ^ { \mathrm { n } _ { \mathrm { l } } } \left[\beta \left(\sum_{\mathrm{j}=1}^{\mathrm{i}-1}(1-\right.\right.\right. \\
& \left.\left.\delta_{l, j}\right) q_{C M}^{\delta_{l, j}} q_{P M}^{-\delta_{l, j}} x_{l, j}\right)\left(\sum_{j=1}^{i-1} q_{C M}^{\delta_{l, j}} q_{P M}^{1-\delta_{l, j}} x_{l, j}\right)^{\beta-1}-\beta\left(\sum_{j=1}^{i-1}(1-\right. \\
& \left.\left.\left.\left.\delta_{l, j}\right) q_{C M}^{\delta_{l, j}} q_{P M}^{-\delta_{l, j}} x_{l, j}\right)\left(\sum_{j=1}^{i-1} q_{C M}^{\delta_{l, j}} q_{P M}^{1-\delta_{l, j}} x_{l, j}+x_{l, i}\right)^{\beta-1}\right]\right]=0
\end{aligned}
$$

Moreover, the estimated reliability parameters are utilized to review the maintenance policies (Guo and Love, 1992; Nodem et al., 2011) of the RS. The cost involved in maintenance actions of RS, whether corrective, preventive or overhaul, is quite high. It becomes even more challenging when these maintenance actions, especially PM and CM are treated as imperfect (Nasr et al., 2013). Generally, overhauling of RS involves major component replacements and repair of the complete system. Also, the cost and time involved in the overhauling process is very high as compared to PM and CM. Hence a down time or cost optimization (Loganathan and Gandhi, 2016; Driessen et al., 2017) is needed to find out the optimal time for an overhaul. The PM can be either time based or age based (Cha et al., 2017; Nguyen et al., 2017). Various time based and age based maintenance policies for non- repairable systems are already in existence in the literature (Makis and Jardine, 1992; Makis and Jardine, 1993). The literature also witnesses various time and age based PM policies considering imperfect maintenance (Wang and Pham, 1996; Jack, 1998; Chen et al., 2016; Nakagawa, 2000). A maintenance policy assuming minimal repair, periodic overhaul and perfect repair is proposed by Zhang and Jardine (1998). Seo and Bai (2004) described the optimal maintenance policy by considering negligible maintenance time and non-negligible maintenance time for the system which is under periodic overhaul. Rai and Bolia (2013) and Rai and Bolia (2014) proposed reliability and availability based optimal maintenance policies to identify the high failure rate components and also review the overhaul cycle using time based downtime 
International Journal of Mathematical, Engineering and Management Sciences

Vol. 6, No. 1, 193-206, 2021

https://doi.org/10.33889/IJMEMS.2021.6.1.012

optimization. Safaei et al. (2019) propose the replacement and repair policies for RS based on probability and mean of profits.

Though the literature is rich enough in providing age based maintenance policies for both nonrepairable (Makis and Jardine, 1992) and repairable systems considering imperfect repair (Wang and Pham, 1996), but very limited papers consider both the PM and CM as imperfect. In addition, the literature lacks in providing optimal age based overhaul policies using downtime optimization which assumes both PM and CM as imperfect for MRS. The literature is also found limited in providing spare parts estimation models for RS considering both the PM and CM as imperfect.

To address the above mentioned research gaps, the paper is structured into two parts: (1) two age based overhaul policies are proposed for MRS using KI model to obtain age based optimal overhaul time when (a) only CM is imperfect (Policy I), and (b) PM and CM both are imperfect (Policy II), (2) the paper also develops a MRS spare part estimation model for both the policies. Although, an aero engine data is taken for validation of the proposed policies, but the same can be applied to similar MRS which undergoes imperfect maintenance and overhaul. The paper is organized as follows: Section 2 develops methodologies for policies I and II to obtain age based optimal time to overhaul for MRS followed by spare parts estimation model. Section 3 presents results and discussions. Section 4 concludes the paper.

\section{Methodology}

In some cases, say, due to difficulties in determining costs or the desire to get maximum throughput or utilization of equipment, the overhaul policy required may be one that minimizes total downtime per unit time or, equivalently, maximizes availability. As the overhaul frequency increases, there is an increase in downtime but the consequence of this is the reduction of downtime due to less number of repair actions, hence the best balance between them is required to be resorted to. Hence, this section develops two different age based overhaul policies which determines the best age at which overhaul should occur to minimize total downtime per unit time. Both the policies are developed for KI model using downtime based optimization technique. Spares parts estimation model is then developed for both the overhaul policies.

Before the age based revised overhaul period is formulated it would be worthwhile to understand the case description along with the existing maintenance policy. The selected case is a turbojet aero engine, a repairable system subjected to general repairs on failing. The aero engines undergo periodic overhauls; original equipment manufacturer (OEM) specified time between overhaul (TBO) being $550 \mathrm{hrs}$. Within an overhaul cycle, the aero engines are subjected to OEM specified periodic time based $\mathrm{PM}$ at fixed intervals of 50 hours (i.e. at $\mathrm{PM}_{1}=50, \mathrm{PM}_{2}=100, \mathrm{PM}_{3}=150 \ldots$. $\mathrm{t}_{\mathrm{o}}=550 \mathrm{hrs}$ ). The existing PM policy for the aero engines is illustrated at Figure 2.

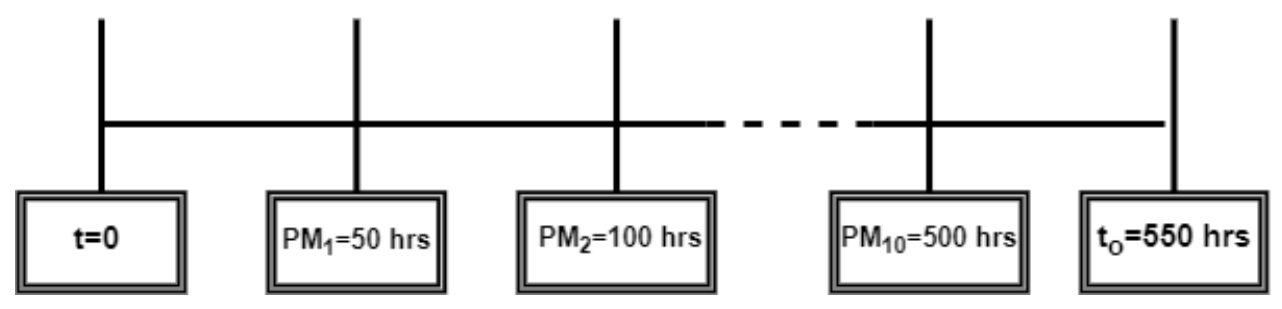

Figure 2. Present maintenance policy. 
International Journal of Mathematical, Engineering and Management Sciences

Vol. 6, No. 1, 193-206, 2021

https://doi.org/10.33889/IJMEMS.2021.6.1.012

\subsection{Age Based Overhaul Period Estimation with Imperfect CM (Policy I)}

The aim is to establish optimal age for overhaul for the next overhaul cycle with the help of existing failure data of the previous overhaul cycle. According to the overhaul policy, overhaul will be done at a fixed age. We determine the optimal age at which the next overhaul should be done so that the high occurrence of failures may be prevented. In the proposed method an overhaul cycle is considered which assumes only imperfect CM as an event and neglect PM. Policy I is explained with the help of Figure 3.

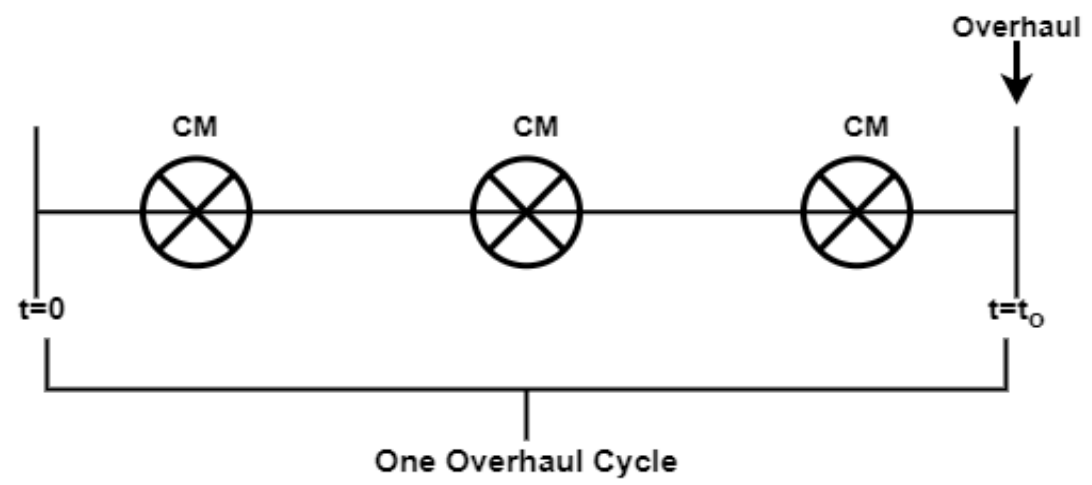

Figure 3. Age based overhaul period estimation with imperfect CM (Policy I).

Downtime per unit time is evaluated with the help of the following method.

Let $\mathrm{D}_{\mathrm{R}}$ be mean downtime required to perform a general repair, $\mathrm{D}_{\mathrm{O}}$ be the downtime required to perform an overhaul. The overhaul policy is to perform overhaul at age $t_{O}$ and general repairs occur as many times as required in the interval $\left(0, \mathrm{t}_{0}\right)$.

The total downtime per unit time, for overhaul at age $t_{0}$, denoted by $\mathrm{D}\left(\mathrm{t}_{\mathrm{O}}\right)$ (Jardine and Tsang, 2005) is :

$D\left(t_{O}\right)=\frac{\begin{array}{c}\text { Expected downtime due to repair } \\ + \text { Expected downtime due to overhaul }\end{array}}{\text { Expected Cycle length }}$

Expected downtime due to repair $=$ Mean downtime due to repair cycle $\left(D_{R}\right) x$ Probability of repair cycle $\left(1-R\left(t_{0}\right)\right)$.

Expected downtime due to overhaul $=$ Downtime due to overhaul $\left(\mathrm{D}_{\mathrm{O}}\right) \times$ Probability of overhaul $\mathrm{R}\left(\mathrm{t}_{\mathrm{O}}\right)$.

Expected cycle length $=$ Overhaul cycle length + Repair cycle length

Overhaul cycle length $=\left(t_{0}+D_{0}\right) R\left(t_{0}\right)$ 
International Journal of Mathematical, Engineering and Management Sciences

Vol. 6, No. 1, 193-206, 2021

https://doi.org/10.33889/IJMEMS.2021.6.1.012

Repair cycle length $=\left[M\left(t_{0}\right)+D_{R}\right]\left[1-R\left(t_{0}\right)\right]$,

where

$M\left(t_{0}\right)=\int_{0}^{t_{0}} t \cdot f(t) d t / 1-R\left(t_{0}\right)$

Therefore

$D\left(t_{0}\right)=\frac{D_{O} R\left(t_{0}\right)+D_{R}\left[1-R\left(t_{0}\right)\right]}{\left(t_{0}+D_{0}\right) R\left(t_{0}\right)+\left[M\left(t_{0}\right)+D_{R}\right]\left[1-R\left(t_{0}\right)\right]}$

Using the above equation, the optimized minimum value of $\mathrm{D}\left(\mathrm{t}_{0}\right)$ can be obtained. The reliability parameters can be estimated using the equations (4-9). The results obtained and discussions thereof are presented in section 3 of the paper.

\subsection{Age Based Overhaul Time Estimation with Imperfect CM and PM (Policy II)}

This section describes the methodology of age based policy considering both CM and PM in one overhaul cycle. Here, both CM and PM are considered as imperfect. It is considered that:

- The operating units of the system are overhauled at every $t_{0}$ i.e. at every $P t_{0}$ where $t_{0}$ is time to overhaul and $\mathrm{P}=1,2,3, \ldots$.

- If the item fails, while in operation at time $t_{f}<t_{0}$; i.e. in interval $\left[(P-1) t_{0},(P-1) t_{0}+t_{f}\right]$, it is subjected to imperfect repair. In addition, the performed PM is scheduled at every 50 hours which is also considered as imperfect (Refer Figure 4)

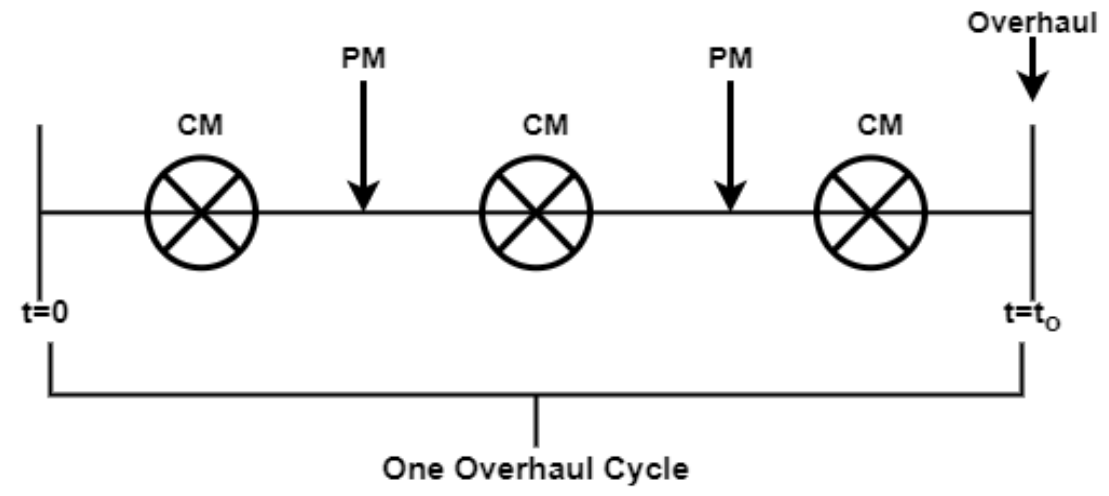

Figure 4. Age based overhaul period estimation with imperfect CM and PM (Policy II).

The first step is to obtain the parameters i.e. $\beta, \eta, q_{C M}$ and $q_{P M}$ and corresponding virtual ages of the field failure data which can be estimated using the equations (1 and 4-9).

Now the downtime equation can be written as: 
International Journal of Mathematical, Engineering and Management Sciences

Vol. 6, No. 1, 193-206, 2021

https://doi.org/10.33889/IJMEMS.2021.6.1.012

$D\left(t_{0}\right)=D_{O}+D_{R} E\left[N\left[0, t_{0}\right]\right]+\frac{t_{0}}{50} D_{P M}$

$\mathrm{E}\left[\mathrm{N}\left[0, \mathrm{t}_{\mathrm{O}}\right]\right]$ : Expected number of failures in interval $\left[0, \mathrm{t}_{\mathrm{O}}\right]$

$\mathrm{E}\left[\mathrm{N}\left[0, \mathrm{t}_{\mathrm{O}}\right]\right]=\int_{0}^{\mathrm{t}_{\mathrm{o}}} \mathrm{u}(\mathrm{t}) \mathrm{dt}$;

where $u(t)=\frac{\beta}{\eta}\left(\frac{t}{\eta}\right)^{\beta-1}$ which is an intensity function of the power law model.

The corresponding virtual age at $t_{0}$ will be $V_{O}$. Thus

$E\left[N\left[0, V_{O}\right]\right]=\int_{0}^{V_{O}} u(v) d v=\frac{v_{0}{ }^{\beta}}{\eta^{\beta}}$

$\mathrm{D}\left(\mathrm{V}_{\mathrm{O}}\right)=\mathrm{D}_{\mathrm{O}}+\mathrm{D}_{\mathrm{R}} \times \mathrm{aV}_{0}{ }^{\beta}+\frac{\mathrm{V}_{\mathrm{O}}}{50} \mathrm{D}_{\mathrm{PM}}$

where $\mathrm{a}=\frac{1}{\eta^{\beta}}$

Downtime per unit time can be expressed as:

$\frac{\mathrm{D}\left(\mathrm{V}_{\mathrm{O}}\right)}{\mathrm{V}_{\mathrm{O}}}=\frac{1}{\mathrm{~V}_{\mathrm{O}}}\left[\mathrm{D}_{\mathrm{O}}+\mathrm{D}_{\mathrm{R}} \times \mathrm{aV}_{0}{ }^{\beta}+\frac{\mathrm{v}_{\mathrm{O}}}{50} \mathrm{D}_{\mathrm{PM}}\right]$

By differentiating the above equation and equating it to zero, the optimal $\mathrm{V}_{\mathrm{O}}$ value can be obtained as:

$\frac{\mathrm{d}}{\mathrm{dV}}\left[\frac{\mathrm{D}\left(\mathrm{V}_{\mathrm{O}}\right)}{\mathrm{V}_{\mathrm{O}}}\right]=\frac{\mathrm{d}}{\mathrm{dV} \mathrm{V}_{0}}\left[\frac{1}{\mathrm{~V}_{\mathrm{O}}}\left[\mathrm{D}_{\mathrm{O}}+\mathrm{D}_{\mathrm{R}} \times \mathrm{aV}_{0}{ }^{\beta}+\frac{\mathrm{V}_{\mathrm{O}}}{50} \mathrm{D}_{\mathrm{PM}}\right]\right]=0$

Hence, the optimal $V_{O}$ can be estimated as:

$\mathrm{V}_{0}=\left[\frac{\mathrm{D}_{\mathrm{O}}}{\mathrm{aD}_{\mathrm{R}}(\beta-1)}\right]^{\frac{1}{\beta}}$

Substituting the values of $\mathrm{D}_{\mathrm{O}}, \mathrm{D}_{\mathrm{R}}, \beta$ and a in equation (17) one can estimate the virtual optimal time for overhaul on the virtual scale and corresponding overhaul time on the real time scale.

\subsection{Spare Parts Estimation}

In this section, a methodology is developed for spare parts estimation for both the policies.

Spare parts estimation (Kececioglu, 2003) in the time interval $\left(t_{2}-t_{1}\right)$, can be formulated as:

$\mathrm{C}_{\mathrm{SP}}\left(\mathrm{t}_{2}-\mathrm{t}_{1}\right)=\mathrm{C}_{\mathrm{T}} \times \mathrm{E}\left[\mathrm{C}_{\mathrm{F}}\left(\mathrm{t}_{2}-\mathrm{t}_{1}\right)\right]$

where

$C_{S P}$ is the total number of expected spare parts in the interval $\left(t_{2}-t_{1}\right)$, 
International Journal of Mathematical, Engineering and Management Sciences

Vol. 6, No. 1, 193-206, 2021

https://doi.org/10.33889/IJMEMS.2021.6.1.012

$\mathrm{C}_{\mathrm{T}}$ is the total number of spare parts in use during the life period $\left(t_{2}-t_{1}\right)$. It is determined either by monitoring such parts or by the theory of maintainability and the PM and CM policy and the schedule used.

$E\left[C_{F}\left(t_{2}-t_{1}\right)\right]$ is expected numbers of failure parts in the interval $\left(t_{2}-t_{1}\right)$.

Thus:

$\mathrm{C}_{\mathrm{SP}}\left(\mathrm{t}_{2}-\mathrm{t}_{1}\right)=\mathrm{C}_{\mathrm{T}} \times \int_{\mathrm{t}_{1}}^{\mathrm{t}_{2}} \mathrm{u}(\mathrm{t}) \mathrm{dt}$

But in this case:

$\mathrm{C}_{\mathrm{SP}}\left(\mathrm{t}_{\mathrm{O}}-0\right)=\mathrm{C}_{\mathrm{T}} \times \int_{0}^{\mathrm{t}_{\mathrm{O}}} \mathrm{u}(\mathrm{t}) \mathrm{dt}$

and in terms of virtual age:

$\mathrm{C}_{\mathrm{SP}}\left(\mathrm{V}_{\mathrm{O}}-0\right)=\mathrm{C}_{\mathrm{T}} \times \int_{0}^{\mathrm{V}_{\mathrm{O}}} \mathrm{u}(\mathrm{v}) \mathrm{dv}$

Hence

$\mathrm{C}_{\mathrm{SP}}\left(\mathrm{V}_{\mathrm{O}}-0\right)=\mathrm{C}_{\mathrm{T}} \times \mathrm{aV}_{0}{ }^{\beta}$

With the values of $C_{T}, a, V_{0}$ and $\beta$ one can estimate the number of spare parts for the particular overhaul time. In addition, the mean time between failures (MTBF) and availability at each data point can be estimated using the following equations:

Mean Time between Failures (MTBF)

$\operatorname{MTBF}\left(\mathrm{V}_{\mathrm{i}}\right)=\frac{1}{\mathrm{u}\left(\mathrm{V}_{\mathrm{i}}\right)}$

Availability

$\mathrm{A}\left(\mathrm{v}_{\mathrm{i}}\right)=\frac{\operatorname{MTBF}\left(\mathrm{v}_{\mathrm{i}}\right)}{\operatorname{MTBF}\left(\mathrm{v}_{\mathrm{i}}\right)+\mathrm{D}_{\mathrm{R}}}$

The results obtained are presented and discussed in the subsequent section.

\section{Results and Discussion}

In this section, the results so estimated for policies I and II are tabulated. From the aero engine manual the value of $\mathrm{D}_{\mathrm{O}}=1900$ hours and the meantime to repair $\mathrm{D}_{\mathrm{R}}=528$ hours. The number of aero engines in use, $\mathrm{C}_{\mathrm{T}}=16$. The model parameters are estimated by maximizing equation (5) using MATLAB and are tabulated in Table 1. The parameters are estimated using Kijima (1989) and Nasr at al. (2013) model and power law model which considers CM as imperfect, PM and CM both as imperfect and minimal CM respectively. To check the fitment of the model, Akaike Information Criterion (AIC) model (equation 5) is used. The model with the minimum AIC estimate is considered as the model with a better fit (Syamsundar and Naikan, 2011). 
International Journal of Mathematical, Engineering and Management Sciences

Vol. 6, No. 1, 193-206, 2021

https://doi.org/10.33889/IJMEMS.2021.6.1.012

$\operatorname{AIC}(H)=-2 \operatorname{LnL}+2 \mathrm{H}$

where $\mathrm{H}$ is the number of parameters in the model.

The results from Table 1 reveal that Nasr at al. (2013) model gives the best fit for the data set. Moreover, the cumulative number of failures plots for each system (total 16 systems) with $90 \%$ confidence bound, considering the base model i.e. power law model, are also shown in Figure 5.

The optimal overhaul time estimated for Policies I and II with the help of equations (10-17) as explained at sections (2.1) and (2.2) respectively are presented at Table 2 . The estimated spare parts as explained at section (2.3) for both the policies are as appended at Table 3.

It can be observed from Tables 2 and 3 that the reviewed overhaul age with Policy I is 416 hours as compared to the existing overhaul time of 550 hours. The availability improvement (equation 24 ) is estimated to be $9.87 \%$ and the number of spare parts that are required for the operation is 28 . Hence there is a reduction in the inventory of spare parts from 42 to 28 . Thus there is a significant savings of $(42-28)=14$ aero engines resulting into a quantum savings in inventory cost.

It can be further noticed that with the reviewed overhaul age with Policy II is 485 hours as compared to the existing overhaul time of 550 hours. The availability improvement (equation 24) is estimated to be $16.6 \%$ and the number of spare parts that are required to be stored is 46 . Hence there is a reduction in the inventory of spare parts from 62 to 46 . Thus there is a significant savings of (62$46)=16$ aero engines once again resulting into desirable reduction in the inventory cost.

Hence it is worth implementing the developed age based overhaul policies (Policy I or II) in place of existing overhaul policy. Both the policies deliver not only a significant improvement in availability of aero engines but also a considerable savings in the inventory cost. Comparing policy I and II, Policy II is more practical as the consideration of PM and CM both being imperfect is taken into account in this case. Also, Policy II provides better results in terms of availability improvement.

Table 1. Estimated reliability parameters considering different models.

\begin{tabular}{|c|c|c|c|c|c|c|c|}
\hline Types of Models & $E\left[C_{F}\left(V_{0}-0\right)\right]$ & $\beta$ & $\eta$ (hours) & $\mathbf{q}_{\mathrm{CM}}$ & $\mathbf{q}_{\mathrm{PM}}$ & $\ln L$ & $\begin{array}{l}\mathrm{AIC} \\
\text { (H) }\end{array}$ \\
\hline $\begin{array}{l}\text { Considering imperfect CM } \\
\text { (Kijima I model) (Policy I) }\end{array}$ & 1.80 & 1.4 & 191.1173 & 0.7 & - & -355.232 & 716.46 \\
\hline $\begin{array}{l}\text { Considering imperfect CM and PM } \\
\text { (Nasr et al. model) } \\
\text { (Policy II) }\end{array}$ & 2.89 & 2.25 & 169.534 & 0.6 & 0.4 & -324.849 & 657.69 \\
\hline Power Law & 4.41 & 1.33 & 180.152 & - & - & -345.327 & 694.65 \\
\hline
\end{tabular}

Table 2. Estimated optimal overhaul time for policies I and II.

\begin{tabular}{c|c}
\hline Policy & t $_{\mathbf{0}}$ (hours) \\
\hline Policy I & 416 \\
\hline Policy II & 485 \\
\hline
\end{tabular}


International Journal of Mathematical, Engineering and Management Sciences

Vol. 6, No. 1, 193-206, 2021

https://doi.org/10.33889/IJMEMS.2021.6.1.012

Table 3. Estimated spare parts for policies I and II.

\begin{tabular}{ccccc}
\hline & $\begin{array}{c}\text { Present Overhaul } \\
\text { Policy (Policy I) }\end{array}$ & $\begin{array}{c}\text { Present Overhaul } \\
\text { Policy } \\
\text { (Policy II) }\end{array}$ & $\begin{array}{c}\text { Reviewed Overhaul } \\
\text { Policy (Policy I) }\end{array}$ & $\begin{array}{c}\text { Reviewed Overhaul Policy } \\
\text { (Policy II) }\end{array}$ \\
\hline $\begin{array}{c}\text { Required Spare } \\
\text { Parts }\end{array}$ & 42 & 62 & 28 & 46 \\
\hline
\end{tabular}

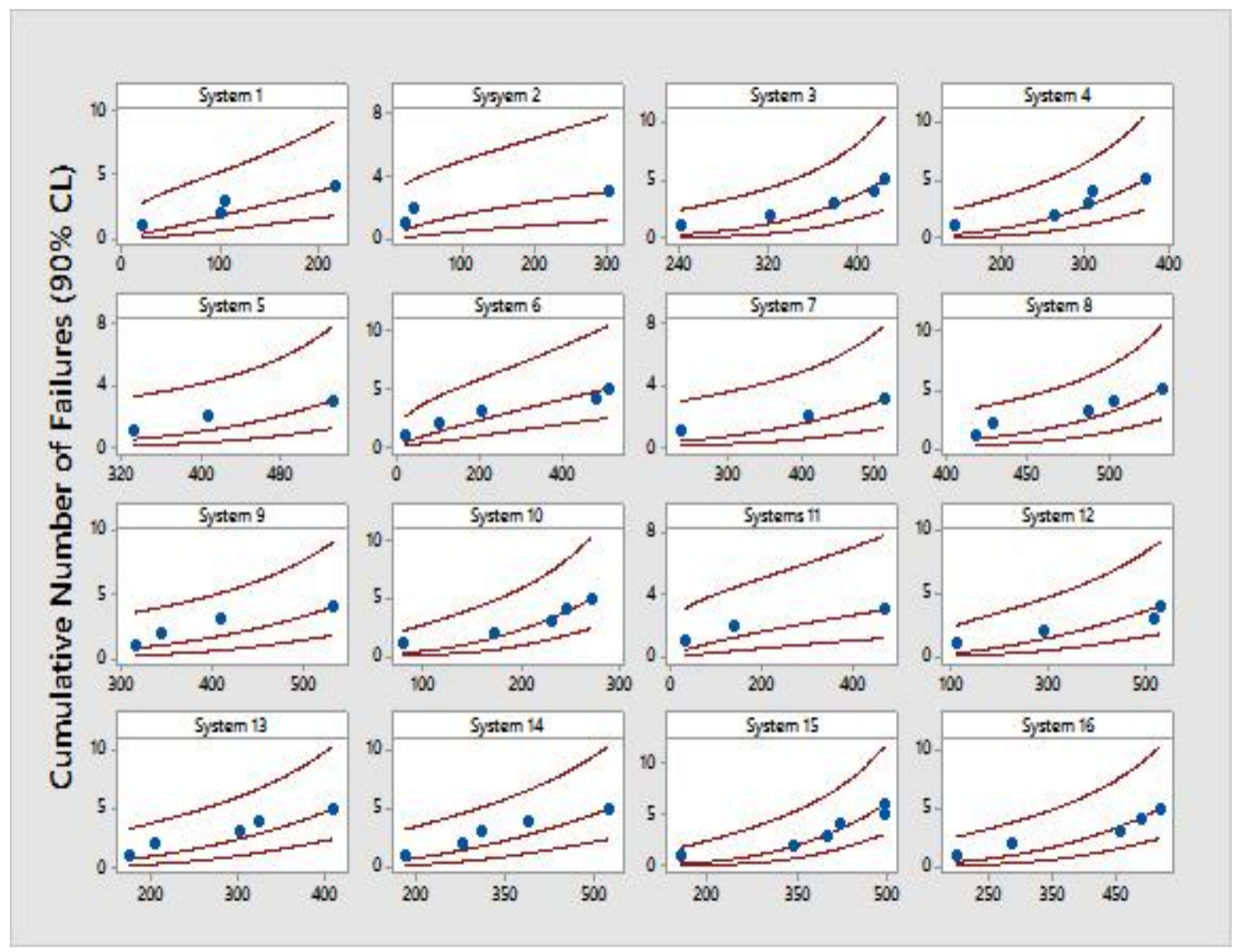

Figure 5. Cumulative number of failures plots for each system.

\section{Conclusion}

The work done in this paper is largely inspired by the industries which deal with repairable systems and face problems in estimating an optimized overhaul time for deteriorating mechanical systems. Considering this issue, this paper proposes two age based overhaul policies (Policy I and Policy II). Policy I considers only CM as imperfect to review the optimal overhaul time whereas Policy II considers $\mathrm{CM}$ and PM both as imperfect. The paper also proposes a spare parts estimation model for the above mentioned overhaul policies (Policy I and Policy II) to evaluate the number of spares required in the inventory. 
International Journal of Mathematical, Engineering and Management Sciences

Vol. 6, No. 1, 193-206, 2021

https://doi.org/10.33889/IJMEMS.2021.6.1.012

All the developed models are validated by considering an aero engine as a case. The aero engines follow a time based scheduled PM policy and is overhauled at a scheduled time of 550 hours. According to the Policy I, the age based optimal overhaul time is estimated to be 416 hours and provides an availability improvement of $9.87 \%$ whereas according to Policy II, the optimal overhaul time comes out to be 485 hours with the availability improvement of $16.6 \%$ when compared to existing overhaul policy for which overhaul time is 550 hours.

There is a significant savings of 14 aero engines resulting into a quantum savings in inventory cost while using Policy I and there is a considerable savings 16 aero engines once again resulting into desirable reduction in the inventory cost when Policy II is used. Hence, it is recommended to implement the developed age based overhaul policies (Policy I or II) in place of existing overhaul policy. There is not only a significant improvement in availability of aero engines but also a considerable savings in the inventory cost. The proposed policies can be applied to any complex MRS which undergoes general repair (CM), PM and overhaul during its life cycle.

\section{Conflict of Interest}

The authors confirm that there is no conflict of interest to declare for this publication.

\section{Acknowledgements}

Authors express their sincere thanks to IIT Kharagpur for providing the research facility.

\section{References}

Bolia, N., \& Rai, R.N. (2013). Reliability based methodologies for optimal maintenance policies in military aviation. International Journal of Performability Engineering, 9(3), 295-303.

Brown, M., \& Proschan, F. (1983). Imperfect repair. Journal of Applied Probability, 20(4), 851-859.

Cha, J.H., Finkelstein, M., \& Levitin, G. (2017). Bivariate preventive maintenance for repairable systems subject to random shocks. Proceedings of the Institution of Mechanical Engineers, Part O: Journal of Risk and Reliability, 231(6), 643-653.

Chen, Y.L., Chang, C.C., \& Sheu, D.F. (2016). Optimum random and age replacement policies for customerdemand multi-state system reliability under imperfect maintenance. International Journal of Systems Science, 47(5), 1130-1141.

Driessen, J.P.C., Peng, H., \& Van Houtum, G.J. (2017). Maintenance optimization under non-constant probabilities of imperfect inspections. Reliability Engineering \& System Safety, 165, 115-123.

Garmabaki, A.H.S., Ahmadi, A., Mahmood, Y.A., \& Barabadi, A. (2016). Reliability modelling of multiple repairable units. Quality and Reliability Engineering International, 32(7), 2329-2343.

Guo, R., \& Love, C.E. (1992). Statistical analysis of an age model for imperfectly repaired systems. Quality and Reliability Engineering International, 8(2), 133-146.

Jack, N. (1998). Age-reduction models for imperfect maintenance. IMA Journal of Management Mathematics, 9(4), 347-354.

Jardine, A.K., \& Tsang, A.H. (2005). Maintenance, replacement, and reliability: Theory and applications. CRC Press, Boca Raton, USA.

Kececioglu, D. (2003). Maintainability, availability, and operational readiness engineering handbook (Vol. 1). DEStech Publications, Inc., USA. 
International Journal of Mathematical, Engineering and Management Sciences

Vol. 6, No. 1, 193-206, 2021

https://doi.org/10.33889/IJMEMS.2021.6.1.012

Kijima, M. (1989). Some results for repairable systems with general repair. Journal of Applied Probability, 26(1), 89-102.

Kijima, M., \& Sumita, U. (1986). A useful generalization of renewal theory: Counting processes governed by non-negative Markovian increments. Journal of Applied Probability, 23(1), 71-88.

Loganathan, M.K., \& Gandhi, O.P. (2016). Maintenance cost minimization of manufacturing systems using PSO under reliability constraint. International Journal of System Assurance Engineering and Management, 7(1), 47-61.

Makis, V., \& Jardine, A.K. (1992). Optimal replacement policy for a general model with imperfect repair. Journal of the Operational Research Society, 43(2), 111-120.

Makis, V., \& Jardine, A.K. (1993). A note on optimal replacement policy under general repair. European Journal of Operational Research, 69(1), 75-82.

Mettas, A., \& Zhao, W. (2005). Modeling and analysis of repairable systems with general repair. In Annual Reliability and Maintainability Symposium, 2005. Proceedings. (pp. 176-182). IEEE. Alexandria, VA, USA.

Nakagawa, T. (2000). Imperfect preventive maintenance models. In Ben-Daya, M., Duffuaa, S.O., \& Raouf, A. (eds.) Maintenance, Modeling and Optimization (pp. 201-214). Springer USA. https://doi.org/10.1007/978-1-4615-4329-9_9.

Nasr, A., Gasmi, S., \& Sayadi, M. (2013). Estimation of the parameters for a complex repairable system with preventive and corrective maintenance. In 2013 International Conference on Electrical Engineering and Software Applications (pp. 1-6). IEEE. Hammamet, Tunisia.

Nguyen, D.T., Dijoux, Y., \& Fouladirad, M. (2017). Analytical properties of an imperfect repair model and application in preventive maintenance scheduling. European Journal of Operational Research, 256(2), 439-453.

Nodem, F.D., Gharbi, A., \& Kenné, J.P. (2011). Preventive maintenance and replacement policies for deteriorating production systems subject to imperfect repairs. International Journal of Production Research, 49(12), 3543-3563.

Pham, H., \& Wang, H. (1996). Imperfect maintenance. European Journal of Operational Research, 94(3), 425-438.

Rai, R.N., \& Bolia, N. (2014). Availability based optimal maintenance policies in military aviation. International Journal of Performability Engineering, 10(6), 641-648.

Rigdon, S.E., \& Basu, A.P. (1989). The power law process: A model for the reliability of repairable systems. Journal of Quality Technology, 21(4), 251-260.

Rigdon, S.E., \& Basu, A.P. (2000). Statistical methods for the reliability of repairable systems. Wiley, New York.

Safaei, F., Ahmadi, J., \& Balakrishnan, N. (2019). A repair and replacement policy for repairable systems based on probability and mean of profits. Reliability Engineering \& System Safety, 183, 1431-52.

Seo, J.H., \& Bai, D.S. (2004). An optimal maintenance policy for a system under periodic overhaul. Mathematical and Computer Modelling, 39(4-5), 373-380.

Sheu, S.H., Dohi, T., \& Wang, W. (2014). Quantitative evaluation in reliability and maintenance. Quality Technology \& Quantitative Management, 11(3), pp. 229-230.

Syamsundar, A., \& Naikan, V.N.A. (2011). Imperfect repair proportional intensity models for maintained systems. IEEE Transactions on Reliability, 60(4), 782-787. 
International Journal of Mathematical, Engineering and Management Sciences

Vol. 6, No. 1, 193-206, 2021

https://doi.org/10.33889/IJMEMS.2021.6.1.012

Wang, H., \& Pham, H. (1996). Optimal maintenance policies for several imperfect repair models. International Journal of Systems Science, 27(6), 543-549.

Yamamoto, H., Ke, J.C., \& Bae, S.J. (2012). Applied Statistics and Reliability Analysis. Quality Technology \& Quantitative Management, 9(3), 229-230. https://doi.org/10.1080/16843703.2012.11673288.

Yanez, M., Joglar, F., \& Modarres, M. (2002). Generalized renewal process for analysis of repairable systems with limited failure experience. Reliability Engineering \& System Safety, 77(2), 167-180.

Zhang, F., \& Jardine, A.K. (1998). Optimal maintenance models with minimal repair, periodic overhaul and complete renewal. IIE Transactions, 30(12), 1109-1119. 